\title{
A BRINCADEIRA DE CONSTRUIR CASINHA
}

\author{
THE HOUSE-BUILDING PLAY
}

Elaine Pedreira Rabinovich *

RABINOVICH, E. R A brincadeira de construir casinha. Rev. Bras. Cresc. Desenv Hum., São Paulo, 9(1), 1999.

Resumo: Este estudo articula a integração entre a atividade lúdica de construir casinha com o desenvolvimento cognitivo-emocional da criança, visto dentro de uma matriz eco-sócio-histórica intergeracional. Nesta articulação, tanto o aspecto genético da capacidade simbólica humana quanto o aspecto genealógico da história do indivíduo são levados em consideração. É relatado um estudo de caso de construção de "cabanas" em uma escola australiana, a partir da literatura, ilustrando o potencial benefício desta atividade do ponto de vista do desenvolvimento infantil, ressaltando as contradições que este mesmo desenvolvimento pode trazer devido às alterações sócio-ambientais.

Palavras-chave: brincadeira de construir casinha; desenvolvimento infantil; relação pessoa/ambiente construído.

\section{INTRODUÇÃO}

Este artigo pretende apresentar alguns aspectos da brincadeira de construir casinha à luz de conceitos desenvolvidos para a análise da moradia (RABINOVICH, 1997). Basear-se-á, igualmente, na prática clínica e nos relatos do Centro de Estudos Casa Redonda, Carapicuíba, São Paulo (PEREIRA \& NUNES, 1989) e no de Kimberly DOVEY (1987) sobre os cerca de 40 anos em que crianças construíram cabanas em uma escola em Melbourne, Austrália.

\section{A CASA COMO SÍMBOLO}

As experiências de ser-no-mundo constituem o come da casa como símbolo, quer nas brincadeiras de construir casa quer nos desenhos de casa. Trata-se de uma experiência de espacializacão, primeira e fundamental, geradora das demais. Trata-se da experiência de habitar o próprio corpo.
São as vicissitudes desta "habitação" ("indwelling” ou personalizarão para (WINNICOTT, 1971) que são “jogadas” nas brincadeiras de casinha. O corpo - o lugar onde se habita - é não apenas o locus de expressão, gostos, sinais, através de uma linguagem corporal a ser lida: ele é o receptáculo das marcas, dores, cicatrizes e tatuagens, - o lugar de sua história. O modo de morar, em sua concretude conforme expresso na moradia, não é um contexto que está fora apenas, mas informa, desde fora, a forma do corpo subjetivo. Segundo PEREIRA \& NUNES (1989), a casa, o corpo e o eu formam uma trindade que se manifesta como um todo nas "brincadeiras de casinha".

É necessário distinguir o símbolo como processo/produto cognitivo, e o símbolo como processo afetivo, pré-verbal, resultado de fusão. A partir das primeiras experiências de não completação do bebê, estar-se-ia formando o processo simbólica, ancorado no diálogo pré-verbal primeiro mãe-criança em que esta institui o reino do imaginário/ sonho/ delírio/ ilusão ao satisfazer o bebê no momento em que este "alucina" o

* Psicóloga clínica, Mestre em Psicologia Experimental/USP, Doutorado em Psicologia Social/USP, pesquisador do C. D.H. e visitante no instituto de Psicologia/USP em pós-doutorado. Bolsista FAPESP. 
“seio”, seio aí significando tudo o que possa ser desejado pelo bebê.

Este diálogo pré-verbal e sincrônico, por sua vez, reproduz as experiências de não comple-tação do adulto, não apenas referidas ao seu passado enquanto bebê, mas ao seu presente nas suas "fissuras" com relação à sociedade. Estas fissuras correspondem às contradições e insatisfações na relação indivíduo-meio. Deste modo, a capacidade simbólica é inerente ao indivíduo, mas seu modo de se concretizar decorre do contexto sócio-cultural.

Como ROSSETTI-FERREIRA, AMORIM \& VITÓRIA (1996), compreendemos que a matriz sócio-cultural que captura mãe e criança, não está fora delas e do meio que as cerca: está na rede de significações que as informam. A rede de significações está expressa no código verbal e no código não-verbal mas, além disto, está expressa em um código espacial, pré-verbal, imagético.

Segundo GUCHT (1990, p. 388), do mesmo modo como a infância é um estado transitório na vida do indivíduo, ela só toma sentido em relação à história, à morfologia e à ideologia da sociedade global e dos grupos sociais no seio das quais ela se integra. Os jogos são reveladores da estrutura do grupo infantil, como de seus ritos, de suas regras e dos seus dramas mas também do imaginário da sociedade global. As sociedades, por sua vez, têm se ocupado em “jogar” sua própria cultura através de grandes sistemas simbólicos que marcam a arte, a organização social e a religião. Para COELHO \& PEDROSA (1995), apoiando-se em WALLON, o tipo de intercâmbio que a criança estabelece com o meio social implica a consideração dos processos históricos da humanidade e é constituído num espaço psíquico que inclui necessidades e desejos.

Estudos sobre o neonato têm demonstrado sua prontidão para sobreviver, extensamente dirigida para o contato social. Diferentemente do que se pensava a partir dos estudos psicanalíticos, há uma separação mãe-criança desde o início de vida desta, tendo a criança um objeto não fantasmático desde este início. O que o bebê teria é uma fusão emocional no sentido de não discriminar a origem das motivações, ou seja, não ser capaz de distinguir entre ele e o outro como iniciadores de ações, como agentes motivacionais.

O corpo seria o lugar de união mãe-criança, e as vicissitudes desta separação, que se dá através das práticas sócio-simbólicas das rotinas de cuidados, passam a estar inscritas no corpo enquanto moradia do ser.

Deste modo, o jogo de construir casinha seria um modo lúdico de ocupar e operar o espaço: ele buscaria expressar uma identidade que o corpo já registra como perda.
As partes que se separam são perdas vividas conforme a rede de significações, não sendo iguais nem entre sociedades nem entre irmãos.

A primeira parte a se destacar é o sono/ vigília. Esta primeira grande separação seria entre consciência/inconsciência, a forma mais rudimentar e total de ser e de ocupar um espaço. Não há divisórias, é tudo/nada, mas há o dia e a noite, a luz e o escuro.

Depois, há a separação dentro/fora: a porta. Posteriormente, em torno deste tema, estabelecer-se-ão diversificações sutis através de janelas, pontes, jardins, quintais, caminhos de chegada-saída, escadas. Já se disse que a casa existe quando há a porta; mas a casa existe antes disto: na caverna, na gruta, no oco, no côncavo.

A segunda separação é a falta, a fome. A fome introduz a cozinha e seus apêndices: poços, fogo, carregar - básicos à vida. Só muito depois, caçar e plantar, ir à feira e comprar.

Como a sensação de fome é destrutiva, ela é cercada de protelares e de rituais de proteção. Inicia-se uma espécie de ordenação bom mau, correspondendo ao desejo de controlar.

Posteriormente, surge a casa como espaço social, passando a ocupar o maior espaço de todos: o jogo de papéis.

Para PEREIRA \& NUNES (1989), na relação com o espaço fisico - casa/corpo - a criança toma consciência de si, em uma organização harmoniosa com o ambiente e construindo-se simultaneamente.

GUCHT (op.cit., p. 391) aponta que o sujeito joga para crer, para se fazer crer ou para fazer crer ao outro que ele é outro que não ele, o que envia a constituição do si mesmo pela interiorização do outro. Este autor defende a sociologia da infância contrapondo-a à psicologia, apontando que o si mesmo (sol mame) não é apenas o eu mesmo (moi mame) dos psicólogos, dado os jogos terem um papel preponderante na formação do si (sol) social e não apenas da personalidade.

No jogo de construção da casa, aparecem as separações através dos corredores, das intermediações, dos quintais, muros, interfaces: as divisões sócio-familiares.

Na brincadeira, há o colocar as coisas no lugar: onde a criança prevê e estabelece a ordem segundo os seus desejos.

O sentido da ordem parece contemplar dois aspectos: de um lado, a especialização propriamente. NISE DA SILVEIRA (1982) aponta a estruturação do espaço como o que garante o homem sadio contra o delírio, como um modo de desenraizar as coisas do corpo e colocá-las no mundo. Não se trata de apenas expressar, mas de existir - ex-stare - estar fora. Este conteúdo exis- 
tencial do construir casinha estaria ligado ao próprio movimento do ser-humano, do ao construir (-se) fazer-se humano (HEIDEGGER, segundo EEFÈBVRE, 1966).

De outro lado, a vivência do tempo cíclico da arrumação em uma repetição dos gostos e do lugar das coisas, organiza o mundo como se ele tivesse ordem. Os eventos se tornam previsíveis, e, portanto , contrapõem- se à imprevisibilidade da morte.

Ao “desenraizar as coisas do corpo”, contudo, a pessoa, adulto ou criança, encontra o outro, segundo as características do tempo vivido. Neste tempo, aparece uma tendência à ordem, oposta ao caos, como intrínseca ao fucionamento psíquico.

Haveria uma “vontade de ordem”, a nosso ver isomórfica ao funcionamento cerebral, refletindo-o. Estudos com bebês (BORNSTEIN, FERDINANDSEN \& GROSS, 1981) mostram que estes preferem certas disposições espaciais a outras, preferindo as mais harmônicas às mais desequilibradas.

As crianças, ao brincar de construir casinha, dispõem em ordem, muitas vezes o jogo sendo apenas isto, acompanhado do imaginário. Pode ser um modo de lidar com as emoções ao expressálas e controlá-las desta forma, mas ao fazê-lo, expressam a natureza matemática do que as leva a fazê-lo. Esta ordenação das coisas no espaço colocaria a criança em harmonia.

O sentido da ordem teria, assim, um caráter afetivo e cognitivo, dentro de uma emergência empática do desenvolvimento cognitivo, sendo a especialização uma experiência a ser compartilhada. O próprio brincar pode ser visto como um construir e compartilhar significados (COELHO \& PEDROSA, op. cit., p. 52), e a brincadeira de construir casinha como um construir em que o imaginário e o significado tomam forma especialmente.

Este movimento para a especialização ocorre no meio, através do meio, como um meio: várias temporalidades, vindas do tempo longo da criação do mundo, do tempo mais breve dos momentos sociais e do tempo instável e curto da história singular, estruturam a forma da especialização, conforme se pode acompanhar pelo relato da experiência em Arlington.

\section{O JOGO DE CONSTRUIR CASINHA}

DOVEY (op. cit.) faz um detalhado relato sobre a evolução da construção de cabanas em uma escola primária australiana. Esta atividade foi iniciada em 1938, tendo cessado em 1981 devido a pressões da vizinhança e da sua interdição pelo Corpo de Bombeiros. O lugar era chamado Arlington, sendo uma parte de uma escola particular. As cabanas foram apoiadas pela direção da escola, de cunho progressista, que priveligiava a iniciativa dos alunos e a integração do aprendizado com a vida cotidiana, de modo que se tornaram uma tradição na escola.

Em termos de ambiente físico, a filosofia educacional da escola resultava em uma falta de distinção entre “classe” e "pátio" e uma forte integração entre atividades internas e externas. A necessidade de expandir a sua área física, face ao crescimento populacional infantil e conseqüente necessidade de fornecer mais áreas para cabanas, contudo, acabou colidindo com a sua própria proposta.

As crianças em Arlington basicamente reconstruiam casinhas palimpsestas, dadas as histórias que elas iam sobrepondo pelas reinserções dos mesmos materiais nos mesmos lugares por crianças diferentes.

Relata DOVEY que, em contraste com as cabanas mais abertas, de ocupação feminina, construídas no nível do chão onde se realizavam principalmente jogos de papéis, as cabanas mais construídas eram pouco usadas após a sua construção. Segundo um dos ex-estudantes: "não me lembro de brincar muito nelas. Elas eram usualmente construídas, deixadas de lado por um tanto, colocadas abaixo, e então uma outra era construída. Era o construir - o chegar lá - era toda a brincadeira”.

A construção do si-próprio envolvido neste jogo corresponde, pois, mais ao ocupar se apropriar - o espaço do que marcá-lo - possuir. Esta distinção entre marcar e ocupar, que emprestamos de DUNCAN (1985), evidencia o aspecto altamente acomodatório, criador, construtor e dinâmico, do construir a casinha, onde a construção é o objetivo principal.

A brincadeira de construir casinha não equiivale, contudo, à de casinha. Nesta, há principalmente o jogo de papéis, enquanto naquela, existiria, em essência, a construção do si próprio.

Em ludoterapia, igualmente, pode-se observar a intensidade do projeto da criança, muitas vezes frustrado na sua conclusão operacional, mas válido por si só, por ocupar uma área intermediária entre o real e o imaginário, como se o encaminhamento do desejo representasse a sua saciação.

Podemos pensar que a brincadeira de "esconde-esconde”, iniciada pelo adulto com bebês em torno dos 9 meses, em que elementos móveis como panos ou almofadas são utilizadas para esconder e fazer reaparecer o rosto adulto ou infantil, seria um precursor da futura brincadeira de construir casinha. Neste jogo, fundamental por demarcar o período do objeto permanente e/ou relação objetal, estaria já presente uma das carac- 
terísticas da casinha que é o segredo, o esconderse, o ter vida própria no sentido de in/tocada. Eqüivaleria ao holding (continência), uma sustentação que possibilita adiar a satisfação das necessidades e tolerar frustração através de uma proteção ambiento-relacional.

A brincadeira de construir casinha pode ser pensada iniciar-se no interior da moradia através do uso não convencional de espaços existentes, como sob a mesa, armário sob a escada, posteriormente construída por elementos móveis como almofadas, etc. Assim, no interior damoradia, teríamos duas categorias: a casinha adaptada ao meio e a casinha “acomodada”, construída a partir dos elementos do meio.

Segundo PEREIRA NUNES (1989), "inicialmente surge a construção de casas individuais. Uma criança organiza o seu espaço, nele entra e permanece algum tempo, deitada, isolando-se do que está à sua volta. O processo ordena-se pela colocação inicial da estrutura do 'entorno' - as paredes, logo segue a ‘cobertura', o teto. No chão, há sempre panos, esteiras, almofadas que, ao serem colocadas, traduzem no gesto da criança uma arrumação de uma cama, um berço, um ninho um lugar de recolhimento, de proteção. Nesse espaço criado há sempre uma caixa ou caixote identificado como ‘porta' através da qual a criança sai ou entra engatinhando” (p. 65).

Posteriormente, com a movimentação no espaço, quando a casa e seus recônditos são utilizados para esconder-se em brincadeiras com outras crianças, amplia-se o uso dos espaços e dos objetos para este ocultamento.

As crianças podem começar a construir casinha a partir dos 5 anos. Podem brincar anteriormente a esta idade, mas de modo imaginário, ou seja, a casinha é construída quase que apenas na imaginação. Conforme DOVEY (op.cit., p. 21), “em um sentido, o processo começava dentro da sala de aula onde pequenos lugares sob as mesas eram apropriados ou criados com panos e caixas de papelão. A criação espontânea de lugares externos emergia entre crianças de 5 anos. Aqui a “cabana” podia ser qualquer coisa, desde um buraco existente, apropriado sem nenhuma transformação, a formas mais construídas tais como tábuas apoiadas contra uma grade ou árvore. A imaginação representava um papel chave nesta idade. Por exemplo, numa “cabana” o único sinal de habitação era um bloco de madeira para sentar. Aos olhos dos ocupantes, contudo, havia paredes, janelas e portas”.

E necessário desenvolvimento e coordenação motora para a construção da casinha, assim como equilíbrio, força física, certa liberdade de ir e vir: ou seja, a criança deve ter alcançado um certo domínio sobre si própria, sobre seu corpo e sobre o ambiente circundante. Um aluno daquela escola recordava-se de sua vivência aos 5 anos, quando “... olhando os grandes que tinham martelos reais, e pregos, e enormes caixas de papelão e árvores e cordas e escadas com as quais criar construções de esplendor quase incrível!” (p. 22).

A casinha no exterior pode estar localizada sob árvores, buracos, ou seja, pela apropriação de espaços já existentes sem qualquer transformação, e pela construção através de materiais coletados e dispostos contra muros, por exemplo. No caso de Arlington, havia três tipos principais de cabanas, construídos principalmente por crianças entre 8 e 11 anos:

- no nível do chão, com tijolos, troncos de madeira, ou linhas riscadas na sujeira demarcando paredes e quartos; eram mais abertos que os outros tipos e existiram enquanto havia espaço e a população de alunos era menor; estavam mais ligados à reprodução de papéis de género, podiam se modificarrapidamente, e desapareceram nos anos 60 com a mudança dos papéis de género e a maior densidade populacional que tornou as simples marcas territoriais vulneráveis;

- no nível do chão, mais construídos e fechados com tábuas; tornaram-se, com o tempo, a ala das cabanas, alinhados contra as cercas laterais; - na árvore, consistindo desde uma plataforma até uma cabana totalmente fechada capaz de acomodar até 5 pessoas.

A casinha pode ser também bidimensional, construída com cartas de baralho, por exemplo, ou tridimensional, quando se pode entrar dentro dela. Embora de caráter totalmente diverso, as duas formas contêm o conteúdo casa. O conteúdo casa existe desde que haja um dentro e um fora, mesmo que apenas representado por uma membrana, como cobrir-se com um cobertor.

A construção da casinha sempre é heterodoxa: há um uso não convencional do espaço e materiais são empregados de modo não ortodoxo, assemelhando-se ao procedimento de bricolage. Neste procedimento, é a dinâmica interna que está conduzindo o processo, sendo o objetivo o resultado a ser conseguido, sem considerações formais. Devido a isto, as cabanas de Arlington tiveram de ser destruídas: pois sua aparência ofendia a vizinhança, assim como a aparência das casinhas construídas pelos sem casa nas ruas paulistanas nos oendem. Houve um movimento da vizinhança contra as casinhas, condenadas pelos bombeiros devido à ameaça de incêndio, embora nos 40 anos nenhum episódio de risco à segurança tivesse ocorrido. 
Após a interdição pelos bombeiros, houve uma tentativa de construção "ortodoxa”, em Arlington: através da mudança de local - de um local central à escola, onde as crianças podiam inclusive espionar o que acontecia ao redor, para uma área frontal, longe dos olhos da vizinhança, e não integrada ao movimento natural na escola; através da mudança de material empregado - de lixo coletado através dos anos, considerado material altamente volátil pelos bombeiros, para material orgânico, folhas, troncos, que não poderiam ser usados de tantos modos quanto a sucata; através da mudança de motivação - da construção espontânea, por vários grupos etários, durante 40 anos de turmas, para uma decorrente de um projeto da classe dos 11 anos, para simular uma comunidade pré-industrial, com regras dadas pelos professores.

Estas regras - todas as casas no nível do chão e longe da visão da vizinhança, fez com que o projeto existisse com entusiasmo devido à camuflagem. Ou seja, não mais motivados internamente, mas externamente. Passado este entusiasmo, abandonou-se as casinhas existentes e não se construiu novas.

Estes exemplos enfatizam o projeto social contido nesta brincadeira, mas pode-se construir casinha solitariamente. O jogo solitário é mais provável ocorrer pela apropriação de espaços preexistentes, enquanto, a nosso ver, a construção estaria mais ligada a uma atividade grupal.

Tanto um quanto outro tipo devem ser compreendidos dentro do contexto mais amplo onde ocorrem. DOVEY analisou como, na escola, o construir cabanas era um processo de negociação informal da realidade social: a ordem espacial e social das relações das pessoas e cabanas, e dessas com a própria escola. "Era uma ordem sócioespacial experienciada antes do que uma imagem visual ordenada, uma ordem que vinha da integração do processo social com o ambiente físico. Em uma idade onde as crianças estavam explorando papéis e identidades e abandonando-os rapidamente, este processo tomava uma forma visível na paisagem das cabanas. E a paisagem era tão dinâmica quanto as transformações pessoais e sociais das próprias crianças, enquanto elas aprendiam e cresciam” (op. cit., p. 24).

DOVEY está, deste modo, apontando a função de integração presente no jogo de construir casa: uma integração tanto de aspectos desconectados subjetivos, como no jogo na clínica psicológica, quanto diretamente ligados ao relacionamento pessoal e social, como descrito acima.

Para GUCHT (op. cit., p. 393), do ponto de vista da sociologia da infância, todo jogo é um fato social, fundamental para a constituição do si pela interiorização do outro. O jogo é uma instituição, ligado a situações socialmente determinadas, cujas estruturas objetivas se exprimem por sistemas de regras, e que se apresenta como uma forma privilegiada de socialização. O próprio imaginar é construir, e não se constrói sem regras, o sentido da regra sendo também o sentido da ordem e, através dela, o domínio de si. É a ordem que a criança integra a seu jogo que permite ou dá a impressão de submeter as coisas a uma ordem imaginária onde intervêm a geometria e a aritmética.

Segundo este autor, Maria MONTESSORI já havia notado o amor à ordem nas crianças de 2 anos, indicando uma afirmação de si própria, mas também a compreensão de uma regra simples. A ordem seria não apenas um comportamento condicionado pelo adulto, mas um sentimento pessoal através do qual a criança pode prever, em seu mundo mental, uma nova ordem dos objetos, que será a expressão de seus desejos próprios.

DOVEY aponta para uma ordem de um outro tipo: a ordem do fechamento, privacidade e controle, "a cabana era a concretização de identidade, e de poder no espaço, do grupo de coetâneos, assim como um refúgio da população escolar mais ampla. (...) O significado de refúgio tornou-se mais importante quando o espaço se tornou escasso. (...) Representava o domínio da vida escolar onde as crianças estavam completamente no controle. A forma exterior da cabana pouco preocupava, mas sim o lugar, tamanho grau de fechamento, propriedade e privacidade eram as preocupações” (op. cit., p. 24).

Conclui seu estudo dizendo que o desenvolvimento da escola se tornou incompatível com o seu próprio projeto de desenvolvimento infantil, conforme manifestada nas cabanas. "O processo de construir cabanas se provou vulnerável, não somente devido a preconceitos estéticos de uma comunidade adulta, mas também pelas atividades de crescimento da própria instituição, que possibilitará o processo de surgimento e sua continuação por 40 anos. A expressão da identidade socialmente negociada em um meio construído, em um nível (o das crianças e de seu desenvolvimento), entraram em conflito com exatamente o mesmo processo em uma escala mais larga (o da escola e de seu desenvolvimento)" (op. cit., p. 26), quando a escola, devido ao seu próprio crescimento, adquiriu novos terrenos, com o desfecho descrito.

PEREIRA \& NUNES analisam o recurso lúdico de construir casinha como um processo contínuo de in-corporação, de tomada de consciência e de construção concomitante do si pró- 
prio. "Como a cidade, o templo, a casa é o lugar no mundo. Uma mediação entre o Céu e a Terra. Um ponto no Universo" (p. 56).

Porém, segundo BIASOLI ALVES (1995), o papel da industrialização ao oferecer brinquedos "educativos" tem uma relação dialética com o comportamento dos pais/educadores, que tentam oferecer às crianças o que é considerado melhor, muitas vezes subestimando o que viveram durante a sua infância. Esta autora aponta também para a crescente urbanização das cidades, onde os espaços de brincar vão sendo reduzidos e ocorrendo em espaços domésticos também diminuídos, donde a ida precoce à escola como solução coloca a criança em atividades programadas.
Face a isto, pergunta-se: como estão as crianças habitando os seus corpos? que "casas" estão construindo para si próprias? como estão negociando as suas identidades através de meios construídos, além dos recursos verbais e/ou de força fisica? como o sentido de ordem está ocorrendo através da apropriação do espaço? onde as crianças podem ter os próprios espaços, de modo ao construir(-se), fazer-se humano?

Do ponto de vista educacional, frente à crescente urbanização e informatização, muitos dos problemas associados a distúrbios psicomotores e psicopedagógicos, assim como a distúrbios comportamentais, apresentados pelas crianças podem ser facilmente traçados a partir das respostas às perguntas acima colocadas.

\begin{abstract}
This study articulares lhe integration between lhe house-building playing activity and lhe child's cognitive and emotional development from an intergenerational eco-socio-historical matrix point of view. In this articulation, lhe genetic aspect of human symbolic activity and lhe genealogical aspect of individual history are taken into account. A study of huts built by students of an Australian school illustrates the potential benefit of this activity to the child's development and, at the same time, shows some contradictions that can emerge from this development due to socio-environmental changes.
\end{abstract}

Key-words: house-building play; child development; person/ built environment relationship.

\section{REFERÊNCIAS BIBLIOGRÁFICAS}

ALVES, R B. A visão dos pais sobre brinquedos, brincadeiras e atividades $\mathrm{r}$ afamilia. Ribeirão Preto, 1995. [Dissertação de Mestrado - Dpto de Psicologia e Educação, Faculdade de Filosofia, Ciências e Letras de Ribeirão Preto, USP].

BORNSTEIN, M. H.; FERDINANDSEN, K.; GROSS. C. G. Perception of syrnmetry in infancy. Developmental Psychology, 17(1): 8286, 1981.

COELHO, M. T. F.; PEDROSA, M. 1. Faz-deconta: construção e compartilhamento de significados. In: OLIVEIRA, Z. d. M. R. d. (org). A criança e seu desenvolvimento: perspectivas para se discutir a educação infantil. São Paulo, Cortez, 1995.

DOVEY, K. The life and death of the Arlington huts. Children s Environments Quarterly, 4(4): 1826, 1987.

DUNCAN, J. S. The house as symbol of social $\operatorname{stn} \sim \mathrm{cn} \wedge$ lre: notes on the language of objecte among collectivistic groups. In: ALTMAN, I.; WERNER, C. M. (eds.) Home environments. New York, PlenumPress, 1985. p. 133-151. v. 8: Humanbehavior and environrnent.
GUCHT, D. V. Activité ludique et sociabilité enfantine: pour une socio-anthropologie de la prime enfance. Revue de l'Institut de Sociologie, 375-398, 1990/1991.

LEFEBVRE, H. Préface. In: RAYMOND, H.; RAYMOND, M. G.; HAUMONT, N.; HAUMONT, A. L 'habitat pavillonnaire. Paris, ISU/Centre de Recherche d'Urbanisme, 1966. p. 3-24.

PEREIRA, M. A.; NUNES, A. A casa, o corpo, o eu: um registro de "brincar de casinha". Boletim de Psicologia, 39(90/91) 55-58, 1989.

RABINOVICH, E. P. Vitrinespelhos transicionais da identidade: um estudo de moradias em espaços sociais liminares brasileiros. São Paulo, 1997. [Tese de Doutorado - instituto de Psicologia, USP].

ROSSETTI-FERREIRA, M. C.; AMORIM, K.; VITORIA, T. Emergência de novos significados durante o processo de adaptação de bebês à creche. Coletanea, ANPEPP, 1996. [s.p.]

SILVEIRA, N. d. Imagens do inconsciente. Rio de Janeiro,Alhambra, 1982.

WINNICOTT, D. W. Le corps et le self. NouvelleRevue dePsychanalyse, 3: 37-48, 1971. 